DMD-MR-2021-000483

\title{
Clinical Relevance of the Constitutive Androstane Receptor
}

\author{
Sydney Stern, Ritika Kurian, and Hongbing Wang
}

Department of Pharmaceutical Sciences, University of Maryland School of Pharmacy, 20 Penn

Street, Baltimore, MD 21201 (S.S., R.K., H.W.) 
DMD-MR-2021-000483

\section{Running title: Clinical relevance of CAR}

Corresponding authors: Hongbing Wang, Ph.D, Department of Pharmaceutical Sciences, University of Maryland School of Pharmacy, 20 Penn Street, Baltimore, MD 21201; Phone: (410)-706-1280; Email: hongbing.wang@rx.umaryland.edu

\section{Document statistics}

Text page: 33

Figures: 2

References: 120

Number of words in Abstract: 160

Number of words in Introduction: 380

Number of words in Conclusion: 467

Number of words in Text: 5,754 
DMD-MR-2021-000483

\begin{abstract}
Constitutive androstane receptor (CAR, NR1I3), a xenobiotic receptor, has long been considered a master mediator of drug disposition and detoxification. Accumulating evidence indicates that CAR also participates in various physiological and pathophysiological pathways regulating the homeostasis of glucose, lipid, and bile acids, and contributes to cell proliferation, tissue regeneration and repair, as well as cancer development. The expression and activity of CAR can be regulated by various factors including small molecular modulators, CAR interaction with other transcription factors, and naturally occurring genetic variants. Given that the influence of CAR has extended beyond the realm of drug metabolism and disposition and has expanded into a potential modulator of human diseases, growing efforts have centered around understanding its clinical relevance and impact on human pathophysiology. This review highlights the current information available regarding the contribution of CAR to various metabolic disorders and cancers and ponders the possible challenges that might arise from pursuing CAR as a potential therapeutic target for these diseases.
\end{abstract}

\title{
Significance statement
}

The growing importance of CAR in glucose and lipid metabolism as well as its potential implication in cell proliferation emphasizes a need to keenly understand the biological function and clinical impact of CAR. This minireview captures the clinical relevance of CAR by highlighting its role in metabolic disorders and cancer development. 
DMD-MR-2021-000483

\section{Abbreviations}

APC, activated protein C; BTSCs, brain tumor stem cells; CAR, constitutive androstane receptor; CITCO, 6-(4-chlorophenyl)imidazo [2,1-beta][1,3]thiazole-5-carbaldehyde- $O$-(3,4dichlorobenzyl)oxime; CYP, cytochrome P450; DBD, DNA-binding domain; DR, direct repeat; DDI, drug-drug interaction; DME, drug-metabolizing enzyme; FAS, fatty acid synthase; FNDC5, fibronectin type III domain-containing protein 5; FOXM1, forkhead box protein M1; FOXO1, forkhead transcription factor; G6Pase, glucose-6-phosphatase; Gadd45 $\beta$, growth arrest and DNA damage-inducible gene $45 \beta$; hCAR, human constitutive androstane receptor; HCC, hepatocellular carcinoma; HFD, high-fat diet; HMGCS2, Hydroxymethylglutaryl-CoA synthase 2; HNF-4 $\alpha$, hepatic nuclear factor $4 \alpha$; HPH, human primary hepatocytes; Insig-1, insulin induced gene 1; IRS, insulin response sequence; LBD, ligand binding domain; MDR1, multi-drug resistance 1; MRP, multi-drug associated protein; PAPS, 3'-phosphoadenosine-5'phosphosulfate; PB, phenobarbital; PBREM, phenobarbital responsive enhancer module; PEPCK1, phosphoenolpyruvate carboxykinase 1; Pfk1, phosphofructokinase; PGC1 $\alpha$, peroxisome proliferator activated receptor- $\gamma$ coactivator- $1 \alpha$; PGD, phosphogluconate dehydrogenase; PKC, protein kinase C; PPAR $\alpha$, peroxisome proliferator-activated receptor $\alpha$; PXR, pregnane X receptor; RIF, rifampicin; RXR, retinoid X receptor; SCD-1, steroyl-CoA desaturase-1; SREBP, sterol regulatory element binding protein; SCAP, SREBP cleavage activating protein; SULT, sulfotransferases; T2D, type 2 diabetes; TCPOBOP, 1,4-bis[2-(3,5dichloropyridylory)] benzene; UGT, uridine diphosphate glucuronosyltransferase; WAT, white adipose tissues; WT, wild-type; XRE, xenobiotic responsive element; YAP, Yes-associated protein 
DMD-MR-2021-000483

\section{Introduction}

The constitutive androstane receptor (CAR, NR1I3), a member of the nuclear receptor superfamily, plays key regulatory functions in many aspects of physiology and development as it exerts ligand-activated transcriptional regulation (Qatanani and Moore, 2005; Negishi, 2017). Originally defined as an orphan nuclear receptor without a clear biological function, CAR has been well-accepted as a master xenosensor of xenobiotic metabolism and disposition (Timsit and Negishi, 2007). Outside the canonical pathway of CAR, mounting evidence suggests CAR may impact various physiological and pathophysiological situations through modulation of energy homeostasis, cell proliferation, and tumor development.

Traditionally, CAR is known for its modulation in hepatic detoxification of xenobiotic and endobiotic chemicals, such as bile acids, bilirubin, and numerous clinically used drugs, where it induces the expression of drug-metabolizing enzymes (DME) and transporters (Wang and LeCluyse, 2003; Timsit and Negishi, 2007; Mackowiak et al., 2018). Consistent with its role in xenobiotic disposition, CAR is highly expressed in the liver and small intestine (Bookout et al., 2006; Yan et al., 2015). Upon activation, cytosolic CAR translocates to the nucleus where it heterodimerizes with retinoid $\mathrm{X}$ receptor $(\mathrm{RXR})$ and binds to the xenobiotic responsive element (XRE), initiating the expression of target genes (Honkakoski and Negishi, 1997; Honkakoski et al., 1998). As a classical nuclear receptor, CAR consists of a common N-terminal activation function 1 ligand-independent domain, a conserved DNA-binding domain (DBD), and a Cterminal ligand binding domain (LBD) (Banerjee et al., 2015). Interestingly, activation of CAR involves both the ligand-dependent (direct) mechanism and a ligand-independent (indirect) mechanism requiring dephosphorylation of CAR mediated by protein phosphatase $2 \mathrm{~A}(\mathrm{PP} 2 \mathrm{~A})$ (Yoshinari et al., 2003; Yang and Wang, 2014). The relatively large LBD of CAR further 
expands the scope of structurally diverse molecules as CAR modulators, influencing metabolism, disposition, and detoxification of xenobiotic and endobiotic molecules (Ekins et al., 2009).

Research thus far has clearly recognized that CAR plays a major regulatory function in xenobiotic metabolism and disposition, dictating drug safety and potential drug-drug interactions (DDI). Its later identified effects on energy homeostasis, cell proliferation, and tissue regeneration hold significant clinical importance (Figure 1). This review aims to discuss the clinical relevance of CAR highlighting its contribution in modulating various disease states, such as metabolic disorders and cancers, thereby, emphasizing CAR as a promising therapeutic target to correct metabolic perturbations.

\section{CAR in Glucose and Lipid Homeostasis}

The role of CAR in energy homeostasis was initially acknowledged when activation of CAR in mice by phenobarbital (PB), a prototypical CAR activator, downregulated a set of genes responsible for gluconeogenesis, fatty acid, and cholesterol biosynthesis (Ueda et al., 2002). Subsequent studies reveal that CAR, in combination with other transcription factors such as the forkhead box protein O1 (FOXO1), peroxisome proliferator-activated receptor $\alpha$ (PPAR $\alpha$ ), and PPAR $\gamma$ coactivator $1 \alpha(\mathrm{PGC} 1 \alpha)$, repress the expression of phosphoenolpyruvate carboxykinase 1 (PEPCK1) and glucose-6-phosphatase (G6Pase) in gluconeogenesis (Kachaylo et al., 2012); sterol regulatory element-binding protein 1c (SREBP1c), acetyl-CoA carboxylase 1, fatty acid synthase (FAS), and steroyl-CoA desaturase-1 (SCD-1) for lipid synthesis (Du et al., 2008); as well as carnitine palmitoyltransferase $\mathrm{I} \alpha(\mathrm{CPT} 1 \alpha)$ and cytosolic Acyl-CoA thioesterase for $\beta$ oxidation (Maglich et al., 2009). Here we focus on recent advances in the role of CAR in energy homeostasis through glucose and lipid metabolism and highlight the therapeutic potential for treating diseases such as obesity and type 2 diabetes (T2D). 
DMD-MR-2021-000483

\subsection{CAR in Glucose Metabolism}

PEPCK1 and G6Pase are two critical gluconeogenic enzymes that catalyze the formation of phosphoenol pyruvate and dephosphorylation of glucose-6-phosphate, respectively. The fact that PB treatment of rat hepatocytes led to marked decrease of glucose production via inhibition of PEPCK1 was realized several years prior to the cloning of CAR (Argaud et al., 1991). Moreover, the use of PB as an adjuvant therapy to sulfonyl urea regimen resulted in an increase in glucose metabolic clearance rate and insulin sensitivity index ultimately leading to a decrease in fasting blood glucose levels (Sotaniemi et al., 1983; Lahtela et al., 1985). Later, a microarray analysis on cDNA obtained from wild-type (WT) and CAR-knockout (-/-) mouse liver samples confirmed, for the first time, that the repressive effect of PB on gluconeogenic genes, such as PEPCK1, G6Pase, and insulin like growth factor-binding protein 1 containing an insulin response sequence (IRS), was a CAR-dependent event (Ueda et al., 2002). In the absence of insulin, FOXO1 directly binds to IRS triggering the transcription of various gluconeogenic genes, thereby, resulting in increased blood glucose levels (Hall et al., 2000; Schmoll et al., 2000). On the other hand, insulin phosphorylates FOXO1 via the phosphoinositide 3-kinase (PI3K)/ protein kinase $\mathrm{B}$ (AKT)-mediated pathway and reduces the binding of FOXO1 to IRS. Employing a combination of yeast two-hybrid screening, glutathione S-transferase pull down, chromatin immunoprecipitation, and animal experiments, Kodama et al. found that CAR and FOXO1 can reciprocally coregulate their respective target genes through cross-talk, where FOXO1-mediated transcription of gluconeogenic genes can be downregulated by CAR acting as a corepressor (Kodama et al., 2004). Hepatic nuclear factor-4 $\alpha(\mathrm{HNF}-4 \alpha)$, an energy sensor, regulates the expression of numerous hepatic genes involved in cholesterol, lipid, and glucose metabolism (Gonzalez, 2008; Yin et al., 2011; Huang et al., 2020). Activation of CAR by 4-[(4R,6R)-4,6- 
diphenyl-1,3-dioxan-2-yl]-N,N-dimethylaniline (transpDMA) significantly reduced fasting blood glucose levels in high-fat-diet (HFD) fed rats via the suppression of PEPCK and G6Pase expression (Yarushkin et al., 2013). Chromatin immunoprecipitation assays further revealed that transpDMA-activated CAR inhibits HNF-4 $\alpha$ transactivation through competition with HNF-4 $\alpha$ for the direct repeat 1 (DR-1) motif in the promoters of these gluconeogenic genes (Yarushkin et al., 2013). This mechanism resembles CAR-mediated repression of CYP7A1 expression through the competition between CAR and HNF-4 $\alpha$ to the DR-1 binding and CYP7A1 transcription (Miao et al., 2006). From an epigenetic perspective, Gao et al. demonstrated that CAR could recruit Cullin 1 E3 ligase-promoting ubiquitination of PGC1 $\alpha$, thus suppressing PGC1 $\alpha$ from being recruited to the proximal promoters of PEPCK1 and G6Pase (Gao et al., 2015). Moreover, studies in human primary hepatocytes (HPH) further confirm the repressive effect of human CAR (hCAR) activation on these gluconeogenic genes (Lynch et al., 2014). Additionally, genome-wide analysis of hCAR transcriptome in wild-type (WT) and hCAR-/- HepaRG cells revealed that the expression of numerous genes associated with energy metabolism was altered when challenged with prototypical hCAR activators such as CITCO (6-(4-chlorophenyl)imidazo [2,1-beta][1,3]thiazole-5-carbaldehyde- $O$-(3,4-dichlorobenzyl)oxime) and PB (Li et al., 2015). However, HepaRG cells which overexpressed CAR that were grown with modified conditions such as high oxygen, medium perfusion, reduced substrate stiffness and 3D conformation, displayed a switch from glycolysis to oxidative phosphorylation by decreasing glucose consumption which overall improved mitochondrial energy metabolism compared to monolayer HepaRG cells (van der Mark et al., 2020).

Utilizing genetically modified animals, Dong et al. reported that hexokinase, an enzyme required for catalyzing the initial irreversible step in glycolysis, is upregulated 2-fold in the liver 
of leptin-deficient (ob/ob) mice, but not in ob/ob, CAR -/- double knockout mice administered 1,4-bis[2-(3,5-dichloropyridylory)] benzene (TCPOBOP), a mouse CAR agonist (Dong et al., 2009). Likewise, activation of CAR also enhanced the expression of phosphogluconate dehydrogenase (PGD), a rate limiting enzyme in the pentose phosphate pathway. Transient transfection assays further illustrated that the proximal promoters of both the hexokinase and PGD genes can be transactivated by CAR (Dong et al., 2009). Recently, results obtained from NMR and LC-MS/MS-based metabolomics in WT and CAR-/- mice showed that activation of CAR by TCPOBOP reduced the level of glucose while increased the abundance of fatty acids, lactate, and ketone bodies in the blood. This metabolic phenotype is correlated with significant downregulation of key gluconeogenic genes and the upregulation of genes in glucose utilization pathways in the liver (Chen et al., 2019). Notably, the expression of glucokinase, an enzyme that converts glucose to glucose-6-phosphate in glycolysis, was nearly doubled when CAR was activated after treatment with TCPOBOP for $48 \mathrm{~h}$. Consistent with previous findings, this study supports an increase in glucose utilization by regulating the pentose phosphate pathway in TCPOBOP treated WT mice indicated by the rise of PGD transcript levels and uridine diphosphate-glucose (Dong et al., 2009; Chen et al., 2019). In another report, Yarushkin et al. demonstrated that following a long-term TCPOBOP treatment ( 8 weeks), a collection of key glycolytic genes including Gck, Gpil, Pfkl, Aldoa, Pgkl, and Pklr are upregulated 2-6 folds in mouse liver (Yarushkin et al., 2016). In parallel to increases in mRNA expression, the hepatic levels of different glycolytic intermediates namely, glucose-6-phosphate and pyruvate were each elevated 1.5 -fold. Thereby, these studies suggest that CAR activation could potentially boost glucose metabolism while having a simultaneously repressive effect on gluconeogenesis.

Irisin is a hormone modified from fibronectin type III domain-containing protein 5 (FNDC5) 
through proteolysis processing and is expressed in skeletal muscles, liver, heart, and adipose tissue (Perakakis et al., 2017). Serum irisin levels detected in T2D patients are low (Choi et al., 2013; Liu et al., 2013). Mo et al. showed that FNDC5 is a direct CAR transcriptional target and activation of CAR leads to hepatic induction of FNDC5 and subsequent elevation of the circulating irisin levels in mice (Mo et al., 2016). Thus, this research offers an alternative route by which CAR activation can influence energy homeostasis and glucose metabolism.

Collectively, CAR-mediated repression of gluconeogenic gene expression occurs through multifaceted signaling that includes inhibition of FOXO1 and IRS interaction, competition with other transcription factors such as HNF-4 $\alpha$ for specific DNA motif binding, and through posttranslational regulation of the subcellular localization and degradation of PGC1 $\alpha$. These studies firmly establish that CAR activity can regulate gluconeogenesis, glucose uptake, and hepatic glycolysis, implying a potential implication of CAR in T2D therapy. Nevertheless, majority of the research thus far has been conducted in rodent animals, comprehensive investigation in human relevant systems is highly demanded to understand the biological role that hCAR asserts.

\subsection{CAR in Lipid Metabolism}

Lipogenesis includes the process of fatty acid synthesis and subsequential triglyceride generation, occurring predominantly in the liver and adipose tissues. Sterol regulatory element binding proteins (SREBPs) are a group of transcription factors known for their regulation of genes involved with cholesterol and fatty acid biosynthesis (Brown and Goldstein, 1997;

Osborne, 2000; Bertolio et al., 2019). Insulin induced gene 1 (Insig-1), an endoplasmic reticulum membrane protein, is one of the upstream regulators of lipogenesis. It has been reported that both Insig-1 and Insig-2 bind to the SREBP cleavage activating protein (SCAP), a protein required for 
DMD-MR-2021-000483

transport and subsequent activation of SREBP transcription factors (Brown and Goldstein, 1997; Edwards et al., 2000). Activation of Insigs however maintains the SCAP-SREBP complex in the endoplasmic reticulum, thus preventing SREBP gene transcription, potentially attenuating fatty acid biosynthesis (Yang et al., 2002).

Early evidence indicated that under HFD feeding, TCPOBOP-mediated activation of CAR noticeably alleviates symptoms of obesity, diabetes, and fatty liver in mice, which is associated with CAR-dependent suppression of SREBP-1c as well as its downstream targets, namely, FAS and SCD-1 (Dong et al., 2009; Gao et al., 2009). Mechanistically, activation of CAR in mouse liver resulted in the induction and activation of Insig-1, which is associated with decreased activation of SREBP-1 along with a $67 \%$ decline of hepatic triglyceride levels (Roth et al., 2008). Further analysis using chromatin immunoprecipitation and in silico genomic analysis identified a DR-4 type response element in the Insig-1 promoter region that responded with high binding affinity to CAR. Importantly, in CAR-/- mice, PB failed to induce Insig-1 expression and did not significantly change the hepatic triglyceride profile compared to WT mice (Roth et al., 2008). The liver X receptor (LXR) is another sterol sensor that promotes lipogenesis through activation of SREBP-1. A mutual suppressive effect between LXR and CAR was recognized, where activation of CAR compromised the LXR agonist responsive recruitment of LXR to SREBP-1c and subsequent lipogenic gene expression, decreasing hepatic triglyceride levels (Zhai et al., 2010). Most recently, Cai et al. showed that in a HFD-induced obesity model, TCPOBOP demonstrated a protective effect on body weight gain and ameliorated insulin sensitivity as expected, while this effect was markedly reduced in mice without expression of the growth arrest and DNA damage-inducible gene $45 \beta$ (Gadd45 $\beta)$, a well-recognized anti-apoptotic factor, acting as a coactivator for CAR (Cai et al., 2021). Loss of Gadd45 $\beta$ is known to impair 
the early transcriptional stimulation caused by CAR activation and hepatomegaly (Tian et al., 2011). While the exact mechanism(s) remains unclear, these studies revealed that CAR requires Gadd $45 \beta$ for mediation of anti-obesity and anti-diabetic effects in vivo by influencing the induction of genes associated with hepatic lipogenesis, gluconeogenesis, and adipose inflammation. Interestingly, although the expression of CAR is trivial in most extrahepatic tissues, such as white adipose tissues (WAT), knockout of Gadd45 $\beta$ abrogates the mitigation of inflammation in WAT by TCPOBOP, a probable secondary metabolic benefit in extrahepatic tissues (Cai et al., 2021). Likewise, Xu et al. observed that TCPOBOP-mediated CAR activation reduces the mammary gland weight approximately by $25 \%$, hinders lipid accumulation via inhibiting lipogenesis and gluconeogenesis in the mammary fat pad, and promotes collagen formation and fibrosis in the mammary glands of female mice (Xu et al., 2018). Collectively, these findings suggest that activation of CAR, which is predominantly expressed in the liver, may profoundly influence systematic energy metabolism in extrahepatic tissues.

In contrast to the beneficial effects of CAR on lipid homeostasis, evidence suggest that CAR activation significantly increases total plasma cholesterol as well as hepatic levels of saturated, monounsaturated, and polyunsaturated fatty acids (Durrington et al., 1976; Calandre et al., 1991; Chen et al., 2019). Moreover, clinical trials have determined that the long-term use of antiepileptic drugs including PB can precipitate the condition of atherosclerosis (Tan et al., 2009). Activation of CAR was also reported to cause a $50 \%$ elevation in blood triglyceride levels by decreasing the expression of PPAR $\alpha$ target genes (Maglich 2009). PPAR $\alpha$ is a transcriptional regulator of genes associated with peroxisomal and mitochondrial $\beta$-oxidation and fatty acid transport; and PPAR $\alpha$ ligands such as fenofibrate and bezafibrate have been clinically used to lower blood triglyceride levels. Subsequent mechanistic studies revealed that both CAR and 
DMD-MR-2021-000483

PPAR $\alpha$ can bind to PGC1 $\alpha$, a coactivator required for PPAR $\alpha$-mediated gene transcription

(Shizu et al., 2020). Through competition, CAR can effectively suppress transcription of PPAR $\alpha$ target genes related to lipid metabolism leading to elevation of blood triglyceride levels in mice (Shizu et al., 2020).

Although the exact reasons for the observed discrepancy of CAR in lipid metabolism remain elusive, information pertaining to the anti-lipogenic effects of CAR was mostly obtained under metabolic and/or nutritional stresses, such as HFD-feeding or caloric restriction. Marmugi et al. demonstrated that TCPOBOP-mediated CAR activation in healthy mice maintained on standard chow markedly increased hepatic triglyceride and cholesterol ester levels in WT but not in CAR/- mice (Marmugi et al., 2016). Under this physiological condition, activation of CAR upregulates the expression of patatin-like phospholipase domain-containing protein 3 (PNPLA3), an emerging marker of liver steatosis, as well as a panel of genes associated with glycolysis and lipogenesis including Fasn, Elovl6, Scd1, and Gpat (Marmugi et al., 2016). In vitro studies using HPH or hepatoma cells also indicated that activation of hCAR by CITCO or PB upregulates hepatic lipogenic genes (Breuker et al., 2010; Marmugi et al., 2016). Dysregulation of lipid biosynthesis as well as its breakdown can lead to obesity and manifest into several other health concerns, such as T2D, non-alcoholic fatty liver disease, and cardiovascular diseases. Notably, CAR mediated regulation of fatty acid metabolism involves a complex interplay of dynamic pathways. The metabolic and nutritional stresses to which mice were subjected may attribute significantly to the anti-lipogenic effects displayed by CAR, hence, not reflecting the true physiological state. Therefore, depending on the exact nature of the impact of CAR in lipogenesis and in maintaining triglyceride levels, CAR may be considered clinically relevant for treating lipid metabolism disorders in a condition specific manner. 
DMD-MR-2021-000483

\subsection{CAR in Bile Acid Metabolism}

Bile acids have long been known to function as physiological detergents, solubilizing circulating cholesterol remnants and fat-soluble vitamins, however accumulation of toxic bile acids in the hepatobiliary system can cause hepatic inflammation, cholestasis, and eventually lead to fibrosis, cirrhosis and even cancers (Narisawa et al., 1974; Radominska et al., 1993). The balance of bile acid synthesis, transport and detoxification is tightly regulated under physiological conditions. Consistent with its promiscuous effects on metabolism, CAR is known to modulate numerous genes associated with bile acid homeostasis including CYP3A for bile acid hydroxylation (Staudinger et al., 2001; Xie et al., 2001; Makishima et al., 2002), uridine diphosphate glucuronosyltransferase (UGTs) for the glucuronic conjugation (Radominska et al., 1990), SULTs for sulfation, and the canalicular bile acid transporter, multidrug resistance associated protein (MRP) 2 (Sugatani et al., 2001; Kast et al., 2002; Huang et al., 2003).

Using transgenic mice, Saini et al. showed that CAR-mediated induction of both SULT and PAPS synthetase 2 (PAPSS2), an enzyme responsible for generating the co-substrate PAPS, can confer resistance to bile acid induced hepatotoxicity (Saini et al., 2004). Sequence analysis identified and characterized an inverted repeats lacking a spacing nucleotide (IR0) in rodent SULT2A gene promoter region that converts CAR-mediated transactivation. Accumulating evidence revealed that activation of CAR is associated with marked reduction of blood levels of bile acid and bilirubin concentrations and can ameliorate cholestasis-induced liver dysfunction, inflammation, and oxidative stress (Guo et al., 2003; Zhang et al., 2004; Stedman et al., 2005; Gabbia et al., 2018). Importantly, both primary and secondary bile acids can function as signaling molecules that modulate the activity of many transcription factors including CAR (Fiorucci et al., 2010). Moreover, through cross-talk and competitive binding to the response 
elements, CAR represses FXR-mediated transcription of CYP7A1, a rate-limiting enzyme converting cholesterol to bile acids in the liver, while FXR exerts suppressive effect on CARinduced MRP4 expression and basolateral bile acid transport (Miao et al., 2006; Renga et al., 2011). Collectively, understanding the interplay between bile acids and CAR and defining the role of CAR in bile acid homeostasis would eventually benefit the identification of new molecules as therapeutic choices for cholestatic liver diseases.

\section{The role of CAR in Cell Proliferation and Cancer Development}

Additional to the role of CAR in energy homeostasis, the impact of CAR on carcinogenesis has been intensely investigated since the initial discovery of PB- and TCPOBOP-mediated liver tumor promotion in mice was validated as a CAR-dependent event (Yamamoto et al., 2004; Huang et al., 2005). Subsequent studies expanded these findings whereby many rodent CAR activators such as cyproconazole (Tamura et al., 2015), metofluthrin (Deguchi et al., 2009), triclosan (Yueh et al., 2014), and propiconazole (Currie et al., 2014), exhibit their non-genotoxic tumor promoting effects by CAR-mediated regulation of liver tumorigenesis (Maeda et al., 2015; Wang et al., 2017).

\subsection{CAR in Rodent Cancer}

To date, activation of CAR has been firmly established as the mode of action by which many PB-like chemicals promote murine liver tumor formation. However, the exact mechanism(s) of CAR-dependent tumor development has not been fully elucidated. A growing body of evidence suggests CAR mediates carcinogenesis through a complex interaction of diverse signaling pathways, promoting hepatocyte proliferation, anti-apoptosis, and tumorigenesis. In this regard, studies exhibited that the activation of CAR modulates the expression of a plethora of genes 
involved in pro-proliferative and oncogenic signaling, such as Gadd45 $\beta$ (Columbano et al., 2005), the murine double minute 2 (Huang et al., 2005), c-Myc and forkhead box M1 (FoxM1) (Blanco-Bose et al., 2008), family with sequence similarity 84 member A (FAM84A) (Kamino et al., 2011b), tubulin alpha 8 (TUBA8) (Kamino et al., 2011a), and cyclin D1 and cyclin dependent kinase 4 (CDK4) (Kazantseva et al., 2013). Interestingly, in addition to its recently realized beneficial effects on CAR-mediated glucose and lipid metabolism, Gadd45 $\beta$, a wellknown anti-apoptotic factor, was markedly induced by TCPOBOP in a CAR-dependent manner, while this induction was independent of tumor necrosis factor $\alpha(\mathrm{TNF} \alpha)$ and nuclear factor kappa B (NFkB) (Columbano et al., 2005). In PB-treated hepatocytes isolated from WT mice, CAR forms a complex with Gadd45 $\beta$ to repress TNF $\alpha$-induced JNK1 phosphorylation and cell death, which was absent in hepatocytes from Car -/- mice (Yamamoto et al., 2010). The interaction between CAR and Gadd45 $\beta$ can also repress the tumor suppressive p38 MAPK signaling (Hori et al., 2018). Notably, knockout of Gadd $45 \beta$ does not significantly affect TCPOBOP stimulated proliferative responses, while largely decreasing the liver/body weight ratio, suggesting loss of Gadd $45 \beta$ may affect CAR-mediated hepatocellular hypertrophy but not hyperplasia (Tian et al., 2011).

Atypical activation of Wnt/ $\beta$-catenin signaling represents a key mediator in the development of many different cancers, including hepatocellular carcinoma (HCC), and is generally considered a robust driver of cell proliferation; nevertheless, hepatic activation of $\beta$-catenin alone does not stimulate liver tumors in mice (Harada et al., 2002). $\beta$-catenin was first linked to CAR by Braeuning et al., where liver-specific knockout of the Ctnnbl gene (encoding for $\beta$-catenin) strongly diminished CAR activation and target gene expression (Braeuning et al., 2009). Subsequent studies revealed that $\beta$-catenin knockout significantly inhibits CAR agonist-induced 
hepatocyte proliferation exclusively in male mice (Braeuning et al., 2011). In 2015, Dong et al. uncovered a unique functional synergy between CAR and $\beta$-catenin in liver tumorigenesis, where dual activation of CAR and $\beta$-catenin results in uncontrolled hepatocyte proliferation and HCC formation (Dong et al., 2015). Consistent with these findings, Aydinlik et al. reported earlier that in diethylnitrosamine plus PB induced murine liver tumors, more than $80 \%$ of them carried an activating $\beta$-catenin mutation, which was markedly higher than that of $28 \%$ in diethylnitrosamine alone induced tumors (Aydinlik et al., 2001). This bidirectional relationship between $\beta$-catenin and CAR dictates the functional requirements of $\beta$-catenin signaling on CARmediated liver tumor promotion and vice versa (Rignall et al., 2011; Ganzenberg et al., 2013).

The Hippo signaling pathway is a chief regulator of organ size in mammals through the regulation of cell proliferation and apoptosis in coordination with the transcriptional co-activator, Yes-associated protein (YAP), as a prominent downstream mediator (Harvey et al., 2013). YAP has also been identified as a prospective mechanism of CAR-mediated liver hyperplasia, where liver enlargement caused by ТСРОВOP was accompanied with increased expression and activation of YAP protein (Kowalik et al., 2011). Moreover, in the diethylnitrosamine plus TCPOBOP HCC model in mice, increased expression of YAP was associated with elevated levels of two YAP target genes namely, alpha-feto-protein and connective tissue growth factor, accompanied by the downregulation of microRNA 375, a known YAP regulator (Kowalik et al., 2011). Recent studies revealed that activation of CAR by TCPOBOP enhanced dephosphorylation and the translocation of YAP from the cytosol to the nucleus where it transcriptionally upregulates cell proliferation (Abe et al., 2018). Alternatively, both knock down of YAP mediated by siRNA and chemical inhibition of YAP/TEAD interaction markedly repressed cell proliferation in a CAR-dependent manner (Abe et al., 2018). Most recently, Gao et 
al. demonstrated that CAR and YAP proteins directly interact with each other following coimmunoprecipitation, additional experiments found that CAR-mediated liver hepatomegaly however was mostly retained in the liver-specific Yap-/- mice (Gao et al., 2021). These findings support the notion that CAR impacts hepatomegaly through complex crosstalk and mediation of multiple signaling pathways with the YAP pathway as one of them.

It should be noted that while a long-term hyperplastic response stimulated by CAR activation could result in liver carcinogenesis, a speedy regenerative response after severe tissue wound is crucial to survival. The regenerative effect of mouse CAR was investigated under extreme ( $91 \%$ liver volume), extended (86\% liver volume), and standard (70\% liver volume) resections (Tschuor et al., 2016). While CAR activity impairment was noted in all mice after extended hepatectomy, standard hepatectomy in CAR-/- mice depicts a phenotype similar to the small-forsize-syndrome observed in mice that underwent extended resection. Following TCPOBOP treatment, pronounced improvement in survival was noted among WT but not CAR-/- mice that received lethal extreme hepatectomy. Mechanistically, the protective effects of TCPOBOP appears to be associated with restoration of the CAR-FoxM1 axis. Collectively, these data uncover CAR as a critical factor mediating recovery of liver failure from extended tissue loss and injury. Moreover, pharmacological activation of CAR might be sufficient to rescue the liver from such damage.

\subsection{CAR in Human Cancer}

In contrast to the well-established tumor promoting effects of CAR on rodent liver stimulated by PB-like compounds, such a mode of action was regarded to be qualitatively questionable for humans (Elcombe et al., 2014). While it has been of heightened interest to determine the potential influence of hCAR activation in developing human cancer, information pertaining to 
the role of hCAR in cancer is relatively scarce (Lake, 2018). Utilizing DNA synthetic activity, Ki67, and proliferating cell nuclear antigen (PCNA) as markers for cell proliferation, previous studies show that PB stimulates murine but not human liver cell proliferation both in vitro in cultured primary hepatocytes and in vivo in WT and human hepatocyte chimeric mice (Parzefall et al., 1991; Yamada et al., 2014). Moreover, epidemiological studies show that PB does not raise the occurrence of liver cancer in humans, even after a long-term exposure at dose levels (100-300 mg daily for 10 years) challenging what was used in rodent liver carcinogenic studies (Olsen et al., 1989; Lamminpaa et al., 2002).

Notably, although hCAR exhibits several mutual features with its rodent counterparts such as induction of DME and xenobiotic transporters, significant interspecies differences of CAR in energy homeostasis and cell proliferation have been documented (Wang and LeCluyse, 2003; Lake, 2018; Mackowiak et al., 2018). Structural comparison of classic nuclear receptors from different species revealed $>90 \%$ sequence conservation in the LBD regions, nevertheless, the LBD sequences of human and mouse CAR share only $71 \%$ amino acid homology (Moore et al., 2002; Qatanani and Moore, 2005). Particularly, TCPOBOP, which has been extensively used as a model mCAR activator in liver cancer studies, does not active hCAR, while as a prototypical hCAR agonist, CITCO actives human but not mouse CAR, making extrapolation of animal data to human challenging (Tzameli et al., 2000; Maglich et al., 2003). To date, our knowledge regarding the role of hCAR in cancer development is limited and seemingly contradictory to that of rodent CAR. Using WT and double humanized PXR and CAR (hPXR/hCAR) C57BL/6J mice, Ross et al. demonstrated that PB treatment increased both hepatocellular hypertrophy and hyperplasia characterized with enhanced cell proliferation in WT mice, while in the hPXR/hCAR-transgenic mice PB intensified hepatocellular hypertrophy without provoking cell 
proliferation (Ross et al., 2010). It is worth noting that although PB activates mouse CAR not mPXR, it is a shared activator of both hCAR and hPXR (Li et al., 2019). Thus, the observed PBinduced hypertrophy in hPXR/hCAR-transgenic mice cannot be exclusively attributed to hCAR. Indeed, the assumed PXR activator, chlordane, caused similar hepatocellular hypertrophy as did PB in the hPXR/hCAR-transgenic mice. Besides pharmacological manipulations, CAR may possess intrinsic endobiotic functions that cannot be suitably explained through chemical stimulation. Transcriptome profiling analysis between WT and CAR-/- HepaRG cells, a surrogate of HPH, revealed that disruption of the "quiescent" hCAR is of particular physiological significance and subsequent pathway analysis indicated that genes related to cell cycle, cancer biology, and cardiovascular diseases are amongst the most enriched pathways in CAR-/HepaRG cells (Li et al., 2015). Meanwhile, analyzing HCC and normal human liver tissue revealed that HCC has increased DNA methylation in the hCAR promoter and lower hCAR expression in comparison to adjacent liver tissues (Tang et al., 2016). Importantly, reduced hCAR expression in HCC is correlated with a worse HCC prognosis (manuscript in preparation).

In addition to HCC, CAR expression and activity was examined in other human cancers such as brain tumors. Brain tumor stem cells (BTSCs) are a key population of tumor cells preserving active proliferation, drug resistance, and recurrence characteristics. Chakraborty et al. demonstrated that CITCO concentration-dependently decreased the growth and expansion of CD133(+) BTSCs by inducing cell cycle detention and apoptosis; the anticancer activity of CITCO is accompanied with potent induction of CAR expression in BTSCs but not in normal astrocytes (Chakraborty et al., 2011). The upregulation of CAR by CITCO in the treatment of glioma depicts a potentially novel treatment approach through targeting BTSCs. Nevertheless, given that CITCO is a known agonist of hCAR not necessarily involving the induction of the 
receptor itself, the exact mechanism underlying this CAR-dependent antineoplastic effect needs be further investigated.

Taken together, mounting evidence suggests that CAR has progressed from a xenobiotic sensor to a signaling molecule that regulates both energy homeostasis and cancer development. While these findings make CAR an attractive therapeutic target with high clinical relevance, significant species-specific differences between human and rodent CAR, particularly in the context of cancer development and cell proliferation, alarm cautious interpretation and extrapolation of data obtained from animal studies (Figure 2). Future extensive research is deemed essential to fill these gaps.

\section{Conclusion}

Over the past two decades, CAR has been known for its involvement in drug metabolism and disposition influencing the pharmacokinetic and toxicological profiles of numerous xenobiotics including environmental chemicals and clinically used drugs, as well as key endobiotics such as bile acids and bilirubin. Thus, activation of CAR is associated with potential DDI leading to clinically detrimental or beneficial consequences. For instance, neonatal jaundice and Gilberts' syndrome, characterized by unconjugated hyperbilirubinemia, can be effectively treated by PB via CAR-mediated induction of UGT1A1, the principal enzyme responsible for the conjugation and clearance of bilirubin (Rossi et al., 2005; Sugatani et al., 2005). In another case, CARmediated induction of CYP2B6, which bioactivates the chemotherapeutic prodrug, cyclophosphamide, has been assessed as a potentially attractive approach for cancer treatment (Wang et al., 2013; Hedrich et al., 2016; Kurian et al., 2020). Although of significant clinical relevance, the topics related to the function of CAR in drug metabolism and DDI has been extensively reviewed previously (Willson and Kliewer, 2002; Wang and LeCluyse, 2003; 
Qatanani and Moore, 2005; Molnar et al., 2013), thus is not a focus of the current mini review.

Unlike typical nuclear receptors that require ligand-dependent activation, CAR activity can be stimulated through various pathways without direct ligand-binding. Emerging evidence indicates CAR has evolved into a signaling molecule that can exhibit functions beyond classical gene transcriptional regulation. The coordination between CAR and other nuclear receptors further complicates the ability to assess the unique role of CAR in certain physiological processes. For instance, CAR and its sister receptor, PXR, share numerous target genes and small molecular modulators. Many so called "selective hCAR modulators," such as CITCO and CINPA1 also activate hPXR (Jeske et al., 2017). In the case of PB, while a CAR activator across multiple species, it also activates human but not mouse PXR. To precisely target and untangle the pathophysiological influence of CAR, better small-molecule compounds and advanced physiologically relevant human models need to be developed to overcome some of these challenges.

Beyond the realm of drug metabolism and disposition, mounting evidence suggests that CAR plays a key role in the modulation of gluconeogenesis, lipogenesis, bile acid regulation, and can influence cell proliferation, tumorigenesis, and inflammation. The pivotal contribution of CAR to these processes may impact the development and treatment of T2D, obesity, and cancers. Nevertheless, the obvious species-specific differences of CAR in energy metabolism and cancer development drastically hinders the interpretation and clinical application of current findings that are predominantly obtained from animal studies. Specifically, current findings strongly support the notion that CAR-mediated mechanism of action for liver tumor development in rodents is irrelevant or opposite from humans. This knowledge gap has motivated a shift in the research focus and warrants more comprehensive studies to fully appreciate the clinical impact of hCAR 
in diseases and drug efficacy.

\section{Acknowledgements}

This minireview is dedicated to Dr. Masahiko Negishi to celebrate his scientific achievements particularly in nuclear receptor regulation of drug metabolism and disposition. Dr. Negishi is also a mentor and long-time collaborator of Hongbing Wang. The authors are thankful to members of the Wang laboratory for discussion and comments on the manuscript. We apologize to the scientists who made contributions to the field however have not been cited because of space limitations.

\section{Authorship Contributions}

Participated in research design: Stern S., Kurian R., Wang H.

Wrote or contributed to the writing of the manuscript: Stern S., Kurian R., Wang H.

\section{Footnote}

This work was partially supported by the National Institutes of Health National Institute of General Medical Sciences [Grant R01GM121550], National Cancer Institute [Grant R01CA262084], and National Institute on Alcohol Abuse and Alcoholism [Grant R21AA028521]. The authors declare there are no actual or perceived conflicts of interest with the contents of this article. 


\section{References}

Abe T, Amaike Y, Shizu R, Takahashi M, Kano M, Hosaka T, Sasaki T, Kodama S, Matsuzawa A, and Yoshinari K (2018) Role of YAP Activation in Nuclear Receptor CAR-Mediated Proliferation of Mouse Hepatocytes. Toxicol Sci 165:408-419.

Argaud D, Halimi S, Catelloni F, and Leverve XM (1991) Inhibition of gluconeogenesis in isolated rat hepatocytes after chronic treatment with phenobarbital. Biochem J 280 ( $\mathbf{P t}$ 3):663-669.

Aydinlik H, Nguyen TD, Moennikes O, Buchmann A, and Schwarz M (2001) Selective pressure during tumor promotion by phenobarbital leads to clonal outgrowth of beta-cateninmutated mouse liver tumors. Oncogene 20:7812-7816.

Banerjee M, Robbins D, and Chen T (2015) Targeting xenobiotic receptors PXR and CAR in human diseases. Drug Discov Today 20:618-628.

Bertolio R, Napoletano F, Mano M, Maurer-Stroh S, Fantuz M, Zannini A, Bicciato S, Sorrentino G, and Del Sal G (2019) Sterol regulatory element binding protein 1 couples mechanical cues and lipid metabolism. Nat Commun 10:1326.

Blanco-Bose WE, Murphy MJ, Ehninger A, Offner S, Dubey C, Huang W, Moore DD, and Trumpp A (2008) C-Myc and its target FoxM1 are critical downstream effectors of constitutive androstane receptor (CAR) mediated direct liver hyperplasia. Hepatology 48:1302-1311.

Bookout AL, Jeong Y, Downes M, Yu RT, Evans RM, and Mangelsdorf DJ (2006) Anatomical profiling of nuclear receptor expression reveals a hierarchical transcriptional network. Cell 126:789-799.

Braeuning A, Heubach Y, Knorpp T, Kowalik MA, Templin M, Columbano A, and Schwarz M (2011) Gender-specific interplay of signaling through beta-catenin and CAR in the regulation of xenobiotic-induced hepatocyte proliferation. Toxicol Sci 123:113-122.

Braeuning A, Sanna R, Huelsken J, and Schwarz M (2009) Inducibility of drug-metabolizing enzymes by xenobiotics in mice with liver-specific knockout of Ctnnb1. Drug Metab Dispos 37:1138-1145.

Breuker C, Moreau A, Lakhal L, Tamasi V, Parmentier Y, Meyer U, Maurel P, Lumbroso S, Vilarem MJ, and Pascussi JM (2010) Hepatic expression of thyroid hormone-responsive spot 14 protein is regulated by constitutive androstane receptor (NR1I3). Endocrinology 151:1653-1661.

Brown MS and Goldstein JL (1997) The SREBP pathway: regulation of cholesterol metabolism by proteolysis of a membrane-bound transcription factor. Cell 89:331-340.

Cai X, Feng Y, Xu M, Yu C, and Xie W (2021) Gadd45b is required in part for the anti-obesity effect of constitutive androstane receptor (CAR). Acta Pharm Sin B 11:434-441.

Calandre EP, Rodriguez-Lopez C, Blazquez A, and Cano D (1991) Serum lipids, lipoproteins and apolipoproteins A and B in epileptic patients treated with valproic acid, carbamazepine or phenobarbital. Acta Neurologica Scandinavica 83:250-253.

Chakraborty S, Kanakasabai S, and Bright JJ (2011) Constitutive androstane receptor agonist CITCO inhibits growth and expansion of brain tumour stem cells. Br J Cancer 104:448459.

Chen F, Coslo DM, Chen T, Zhang L, Tian Y, Smith PB, Patterson AD, and Omiecinski CJ (2019) Metabolomic Approaches Reveal the Role of CAR in Energy Metabolism. $J$ Proteome Res 18:239-251. 
Choi YK, Kim MK, Bae KH, Seo HA, Jeong JY, Lee WK, Kim JG, Lee IK, and Park KG (2013) Serum irisin levels in new-onset type 2 diabetes. Diabetes Res Clin Pract 100:96-101.

Columbano A, Ledda-Columbano GM, Pibiri M, Cossu C, Menegazzi M, Moore DD, Huang W, Tian J, and Locker J (2005) Gadd45beta is induced through a CAR-dependent, TNFindependent pathway in murine liver hyperplasia. Hepatology 42:1118-1126.

Currie RA, Peffer RC, Goetz AK, Omiecinski CJ, and Goodman JI (2014) Phenobarbital and propiconazole toxicogenomic profiles in mice show major similarities consistent with the key role that constitutive androstane receptor (CAR) activation plays in their mode of action. Toxicology 321:80-88.

Deguchi Y, Yamada T, Hirose Y, Nagahori H, Kushida M, Sumida K, Sukata T, Tomigahara Y, Nishioka K, Uwagawa S, Kawamura S, and Okuno Y (2009) Mode of action analysis for the synthetic pyrethroid metofluthrin-induced rat liver tumors: evidence for hepatic CYP2B induction and hepatocyte proliferation. Toxicol Sci 108:69-80.

Dong B, Lee JS, Park YY, Yang F, Xu G, Huang W, Finegold MJ, and Moore DD (2015) Activating CAR and beta-catenin induces uncontrolled liver growth and tumorigenesis. Nat Commun 6:5944.

Dong B, Saha PK, Huang W, Chen W, Abu-Elheiga LA, Wakil SJ, Stevens RD, Ilkayeva O, Newgard CB, Chan L, and Moore DD (2009) Activation of nuclear receptor CAR ameliorates diabetes and fatty liver disease. Proc Natl Acad Sci U S A 106:18831-18836.

Du J, Chen Q, Takemori H, and Xu H (2008) SIK2 can be activated by deprivation of nutrition and it inhibits expression of lipogenic genes in adipocytes. Obesity (Silver Spring) 16:531-538.

Durrington PN, Roberts CJ, Jackson L, Branch RA, and Hartog M (1976) Effect of phenobarbitone on plasma lipids in normal subjects. Clinical science and molecular medicine 50:349-353.

Edwards PA, Tabor D, Kast HR, and Venkateswaran A (2000) Regulation of gene expression by SREBP and SCAP. Biochim Biophys Acta 1529:103-113.

Ekins S, Kortagere S, Iyer M, Reschly EJ, Lill MA, Redinbo MR, and Krasowski MD (2009) Challenges predicting ligand-receptor interactions of promiscuous proteins: the nuclear receptor PXR. PLoS Comput Biol 5:e1000594.

Elcombe CR, Peffer RC, Wolf DC, Bailey J, Bars R, Bell D, Cattley RC, Ferguson SS, Geter D, Goetz A, Goodman JI, Hester S, Jacobs A, Omiecinski CJ, Schoeny R, Xie W, and Lake BG (2014) Mode of action and human relevance analysis for nuclear receptor-mediated liver toxicity: A case study with phenobarbital as a model constitutive androstane receptor (CAR) activator. Critical reviews in toxicology 44:64-82.

Fiorucci S, Cipriani S, Baldelli F, and Mencarelli A (2010) Bile acid-activated receptors in the treatment of dyslipidemia and related disorders. Progress in lipid research 49:171-185.

Gabbia D, Pozzo L, Zigiotto G, Roverso M, Sacchi D, Dalla Pozza A, Carrara M, Bogialli S, Floreani A, Guido M, and De Martin S (2018) Dexamethasone counteracts hepatic inflammation and oxidative stress in cholestatic rats via CAR activation. PLoS One 13:e0204336.

Ganzenberg K, Singh Y, and Braeuning A (2013) The time point of beta-catenin knockout in hepatocytes determines their response to xenobiotic activation of the constitutive androstane receptor. Toxicology 308:113-121.

Gao J, He J, Zhai Y, Wada T, and Xie W (2009) The constitutive androstane receptor is an antiobesity nuclear receptor that improves insulin sensitivity. J Biol Chem 284:25984-25992. 
Gao J, Yan J, Xu M, Ren S, and Xie W (2015) CAR Suppresses Hepatic Gluconeogenesis by Facilitating the Ubiquitination and Degradation of PGC1alpha. Mol Endocrinol 29:15581570.

Gao Y, Fan S, Li H, Jiang Y, Yao X, Zhu S, Yang X, Wang R, Tian J, Gonzalez FJ, Huang M, and $\mathrm{Bi} \mathrm{H}$ (2021) Constitutive androstane receptor induced-hepatomegaly and liver regeneration is partially via yes-associated protein activation. Acta Pharm Sin B 11:727737.

Gonzalez FJ (2008) Regulation of hepatocyte nuclear factor 4 alpha-mediated transcription. Drug metabolism and pharmacokinetics 23:2-7.

Guo GL, Lambert G, Negishi M, Ward JM, Brewer HB, Jr., Kliewer SA, Gonzalez FJ, and Sinal CJ (2003) Complementary roles of farnesoid X receptor, pregnane X receptor, and constitutive androstane receptor in protection against bile acid toxicity. J Biol Chem 278:45062-45071.

Hall RK, Yamasaki T, Kucera T, Waltner-Law M, O'Brien R, and Granner DK (2000) Regulation of phosphoenolpyruvate carboxykinase and insulin-like growth factor-binding protein-1 gene expression by insulin. The role of winged helix/forkhead proteins. J Biol Chem 275:30169-30175.

Harada N, Miyoshi H, Murai N, Oshima H, Tamai Y, Oshima M, and Taketo MM (2002) Lack of tumorigenesis in the mouse liver after adenovirus-mediated expression of a dominant stable mutant of beta-catenin. Cancer research 62:1971-1977.

Harvey KF, Zhang X, and Thomas DM (2013) The Hippo pathway and human cancer. Nature reviews Cancer 13:246-257.

Hedrich WD, Xiao J, Heyward S, Zhang Y, Zhang J, Baer MR, Hassan HE, and Wang H (2016) Activation of the Constitutive Androstane Receptor Increases the Therapeutic Index of CHOP in Lymphoma Treatment. Mol Cancer Ther 15:392-401.

Honkakoski P and Negishi M (1997) Characterization of a phenobarbital-responsive enhancer module in mouse P450 Cyp2b10 gene. J Biol Chem 272:14943-14949.

Honkakoski P, Zelko I, Sueyoshi T, and Negishi M (1998) The nuclear orphan receptor CARretinoid $\mathrm{X}$ receptor heterodimer activates the phenobarbital-responsive enhancer module of the CYP2B gene. Mol Cell Biol 18:5652-5658.

Hori T, Saito K, Moore R, Flake GP, and Negishi M (2018) Nuclear Receptor CAR Suppresses GADD45B-p38 MAPK Signaling to Promote Phenobarbital-induced Proliferation in Mouse Liver. Molecular cancer research : MCR 16:1309-1318.

Huang KW, Reebye V, Czysz K, Ciriello S, Dorman S, Reccia I, Lai HS, Peng L, Kostomitsopoulos N, Nicholls J, Habib RS, Tomalia DA, Saetrom P, Wilkes E, Cutillas P, Rossi JJ, and Habib NA (2020) Liver Activation of Hepatocellular Nuclear Factor4alpha by Small Activating RNA Rescues Dyslipidemia and Improves Metabolic Profile. Mol Ther Nucleic Acids 19:361-370.

Huang W, Zhang J, Chua SS, Qatanani M, Han Y, Granata R, and Moore DD (2003) Induction of bilirubin clearance by the constitutive androstane receptor (CAR). Proc Natl Acad Sci U S A 100:4156-4161.

Huang W, Zhang J, Washington M, Liu J, Parant JM, Lozano G, and Moore DD (2005) Xenobiotic stress induces hepatomegaly and liver tumors via the nuclear receptor constitutive androstane receptor. Mol Endocrinol 19:1646-1653. 
Jeske J, Windshugel B, Thasler WE, Schwab M, and Burk O (2017) Human pregnane X receptor is activated by dibenzazepine carbamate-based inhibitors of constitutive androstane receptor. Arch Toxicol 91:2375-2390.

Kachaylo EM, Yarushkin AA, and Pustylnyak VO (2012) Constitutive androstane receptor activation by 2,4,6-triphenyldioxane-1,3 suppresses the expression of the gluconeogenic genes. Eur J Pharmacol 679:139-143.

Kamino H, Moore R, and Negishi M (2011a) Role of a novel CAR-induced gene, TUBA8, in hepatocellular carcinoma cell lines. Cancer Genet 204:382-391.

Kamino H, Yamazaki Y, Saito K, Takizawa D, Kakizaki S, Moore R, and Negishi M (2011b) Nuclear receptor CAR-regulated expression of the FAM84A gene during the development of mouse liver tumors. International journal of oncology 38:1511-1520.

Kast HR, Goodwin B, Tarr PT, Jones SA, Anisfeld AM, Stoltz CM, Tontonoz P, Kliewer S, Willson TM, and Edwards PA (2002) Regulation of multidrug resistance-associated protein 2 (ABCC2) by the nuclear receptors pregnane $\mathrm{X}$ receptor, farnesoid $\mathrm{X}$-activated receptor, and constitutive androstane receptor. J Biol Chem 277:2908-2915.

Kazantseva YA, Yarushkin AA, and Pustylnyak VO (2013) Dichlorodiphenyltrichloroethane technical mixture regulates cell cycle and apoptosis genes through the activation of CAR and ERalpha in mouse livers. Toxicol Appl Pharmacol 271:137-143.

Kodama S, Koike C, Negishi M, and Yamamoto Y (2004) Nuclear receptors CAR and PXR cross talk with FOXO1 to regulate genes that encode drug-metabolizing and gluconeogenic enzymes. Mol Cell Biol 24:7931-7940.

Kowalik MA, Saliba C, Pibiri M, Perra A, Ledda-Columbano GM, Sarotto I, Ghiso E, Giordano S, and Columbano A (2011) Yes-associated protein regulation of adaptive liver enlargement and hepatocellular carcinoma development in mice. Hepatology 53:20862096.

Kurian R, Hedrich W, Mackowiak B, Li L, and Wang H (2020) CITCO as an Adjuvant Facilitates CHOP-Based Lymphoma Treatment in hCAR-Transgenic Mice. Cells $\mathbf{9}$.

Lahtela JT, Arranto AJ, and Sotaniemi EA (1985) Enzyme inducers improve insulin sensitivity in non-insulin-dependent diabetic subjects. Diabetes 34:911-916.

Lake BG (2018) Human relevance of rodent liver tumour formation by constitutive androstane receptor (CAR) activators. Toxicol Res (Camb) 7:697-717.

Lamminpaa A, Pukkala E, Teppo L, and Neuvonen PJ (2002) Cancer incidence among patients using antiepileptic drugs: a long-term follow-up of 28,000 patients. Eur J Clin Pharmacol 58:137-141.

Li D, Mackowiak B, Brayman TG, Mitchell M, Zhang L, Huang SM, and Wang H (2015) Genome-wide analysis of human constitutive androstane receptor (CAR) transcriptome in wild-type and CAR-knockout HepaRG cells. Biochem Pharmacol 98:190-202.

Li L, Welch MA, Li Z, Mackowiak B, Heyward S, Swaan PW, and Wang H (2019) Mechanistic Insights of Phenobarbital-Mediated Activation of Human but Not Mouse Pregnane X Receptor. Mol Pharmacol 96:345-354.

Liu JJ, Wong MD, Toy WC, Tan CS, Liu S, Ng XW, Tavintharan S, Sum CF, and Lim SC (2013) Lower circulating irisin is associated with type 2 diabetes mellitus. J Diabetes Complications 27:365-369.

Lynch C, Pan Y, Li L, Heyward S, Moeller T, Swaan PW, and Wang H (2014) Activation of the constitutive androstane receptor inhibits gluconeogenesis without affecting lipogenesis or 
fatty acid synthesis in human hepatocytes. Toxicology and applied pharmacology 279:33-42.

Mackowiak B, Hodge J, Stern S, and Wang H (2018) The Roles of Xenobiotic Receptors: Beyond Chemical Disposition. Drug Metab Dispos 46:1361-1371.

Maeda J, Inoue K, Ichimura R, Takahashi M, Kodama Y, Saito N, and Yoshida M (2015) Essential role of constitutive androstane receptor in Ginkgo biloba extract induced liver hypertrophy and hepatocarcinogenesis. Food and chemical toxicology : an international journal published for the British Industrial Biological Research Association 83:201-209.

Maglich JM, Lobe DC, and Moore JT (2009) The nuclear receptor CAR (NR1I3) regulates serum triglyceride levels under conditions of metabolic stress. J Lipid Res 50:439-445.

Maglich JM, Parks DJ, Moore LB, Collins JL, Goodwin B, Billin AN, Stoltz CA, Kliewer SA, Lambert MH, Willson TM, and Moore JT (2003) Identification of a novel human constitutive androstane receptor (CAR) agonist and its use in the identification of CAR target genes. J Biol Chem 278:17277-17283.

Makishima M, Lu TT, Xie W, Whitfield GK, Domoto H, Evans RM, Haussler MR, and Mangelsdorf DJ (2002) Vitamin D receptor as an intestinal bile acid sensor. Science 296:1313-1316.

Marmugi A, Lukowicz C, Lasserre F, Montagner A, Polizzi A, Ducheix S, Goron A, GametPayrastre L, Gerbal-Chaloin S, Pascussi JM, Moldes M, Pineau T, Guillou H, and MselliLakhal L (2016) Activation of the Constitutive Androstane Receptor induces hepatic lipogenesis and regulates Pnpla3 gene expression in a LXR-independent way. Toxicol Appl Pharmacol 303:90-100.

Miao J, Fang S, Bae Y, and Kemper JK (2006) Functional inhibitory cross-talk between constitutive androstane receptor and hepatic nuclear factor-4 in hepatic lipid/glucose metabolism is mediated by competition for binding to the DR1 motif and to the common coactivators, GRIP-1 and PGC-1alpha. J Biol Chem 281:14537-14546.

Mo L, Shen J, Liu Q, Zhang Y, Kuang J, Pu S, Cheng S, Zou M, Jiang W, Jiang C, Qu A, and He J (2016) Irisin Is Regulated by CAR in Liver and Is a Mediator of Hepatic Glucose and Lipid Metabolism. Mol Endocrinol 30:533-542.

Molnar F, Kublbeck J, Jyrkkarinne J, Prantner V, and Honkakoski P (2013) An update on the constitutive androstane receptor (CAR). Drug metabolism and drug interactions 28:7993.

Moore LB, Maglich JM, McKee DD, Wisely B, Willson TM, Kliewer SA, Lambert MH, and Moore JT (2002) Pregnane X receptor (PXR), constitutive androstane receptor (CAR), and benzoate $\mathrm{X}$ receptor (BXR) define three pharmacologically distinct classes of nuclear receptors. Mol Endocrinol 16:977-986.

Narisawa T, Magadia NE, Weisburger JH, and Wynder EL (1974) Promoting effect of bile acids on colon carcinogenesis after intrarectal instillation of N-methyl-N'-nitro-Nnitrosoguanidine in rats. Journal of the National Cancer Institute 53:1093-1097.

Negishi M (2017) Phenobarbital Meets Phosphorylation of Nuclear Receptors. Drug Metab Dispos 45:532-539.

Olsen JH, Boice JD, Jr., Jensen JP, and Fraumeni JF, Jr. (1989) Cancer among epileptic patients exposed to anticonvulsant drugs. Journal of the National Cancer Institute 81:803-808.

Osborne TF (2000) Sterol regulatory element-binding proteins (SREBPs): key regulators of nutritional homeostasis and insulin action. J Biol Chem 275:32379-32382. 
Parzefall W, Erber E, Sedivy R, and Schulte-Hermann R (1991) Testing for induction of DNA synthesis in human hepatocyte primary cultures by rat liver tumor promoters. Cancer research 51:1143-1147.

Perakakis N, Triantafyllou GA, Fernandez-Real JM, Huh JY, Park KH, Seufert J, and Mantzoros CS (2017) Physiology and role of irisin in glucose homeostasis. Nat Rev Endocrinol 13:324-337.

Qatanani M and Moore DD (2005) CAR, the continuously advancing receptor, in drug metabolism and disease. Curr Drug Metab 6:329-339.

Radominska A, Comer KA, Zimniak P, Falany J, Iscan M, and Falany CN (1990) Human liver steroid sulphotransferase sulphates bile acids. Biochem J 272:597-604.

Radominska A, Treat S, and Little J (1993) Bile acid metabolism and the pathophysiology of cholestasis. Seminars in liver disease 13:219-234.

Renga B, Migliorati M, Mencarelli A, Cipriani S, D'Amore C, Distrutti E, and Fiorucci S (2011) Farnesoid $\mathrm{X}$ receptor suppresses constitutive androstane receptor activity at the multidrug resistance protein-4 promoter. Biochim Biophys Acta 1809:157-165.

Rignall B, Braeuning A, Buchmann A, and Schwarz M (2011) Tumor formation in liver of conditional beta-catenin-deficient mice exposed to a diethylnitrosamine/phenobarbital tumor promotion regimen. Carcinogenesis 32:52-57.

Ross J, Plummer SM, Rode A, Scheer N, Bower CC, Vogel O, Henderson CJ, Wolf CR, and Elcombe CR (2010) Human constitutive androstane receptor (CAR) and pregnane X receptor (PXR) support the hypertrophic but not the hyperplastic response to the murine nongenotoxic hepatocarcinogens phenobarbital and chlordane in vivo. Toxicol Sci 116:452-466.

Rossi F, Francese M, Iodice RM, Falcone E, Vetrella S, Punzo F, De Vita S, and Perrotta S (2005) [Inherited disorders of bilirubin metabolism]. Minerva pediatrica 57:53-63.

Roth A, Looser R, Kaufmann M, Blattler SM, Rencurel F, Huang W, Moore DD, and Meyer UA (2008) Regulatory cross-talk between drug metabolism and lipid homeostasis: constitutive androstane receptor and pregnane $\mathrm{X}$ receptor increase Insig-1 expression. Mol Pharmacol 73:1282-1289.

Saini SP, Sonoda J, Xu L, Toma D, Uppal H, Mu Y, Ren S, Moore DD, Evans RM, and Xie W (2004) A novel constitutive androstane receptor-mediated and CYP3A-independent pathway of bile acid detoxification. Mol Pharmacol 65:292-300.

Schmoll D, Walker KS, Alessi DR, Grempler R, Burchell A, Guo S, Walther R, and Unterman TG (2000) Regulation of glucose-6-phosphatase gene expression by protein kinase Balpha and the forkhead transcription factor FKHR. Evidence for insulin response unitdependent and -independent effects of insulin on promoter activity. J Biol Chem 275:36324-36333.

Shizu R, Otsuka Y, Ezaki K, Ishii C, Arakawa S, Amaike Y, Abe T, Hosaka T, Sasaki T, Kanno Y, Miyata M, Yamazoe Y, and Yoshinari K (2020) Antiepileptic Drug-Activated Constitutive Androstane Receptor Inhibits Peroxisome Proliferator-Activated Receptor alpha and Peroxisome Proliferator-Activated Receptor gamma Coactivator 1alphaDependent Gene Expression to Increase Blood Triglyceride Levels. Mol Pharmacol 98:634-647.

Sotaniemi EA, Arranto AJ, Sutinen S, Stengard JH, and Sutinen S (1983) Treatment of noninsulin-dependent diabetes mellitus with enzyme inducers. Clin Pharmacol Ther 33:826-835. 
Staudinger JL, Goodwin B, Jones SA, Hawkins-Brown D, MacKenzie KI, LaTour A, Liu Y, Klaassen CD, Brown KK, Reinhard J, Willson TM, Koller BH, and Kliewer SA (2001) The nuclear receptor PXR is a lithocholic acid sensor that protects against liver toxicity. Proc Natl Acad Sci U S A 98:3369-3374.

Stedman CA, Liddle C, Coulter SA, Sonoda J, Alvarez JG, Moore DD, Evans RM, and Downes M (2005) Nuclear receptors constitutive androstane receptor and pregnane X receptor ameliorate cholestatic liver injury. Proc Natl Acad Sci U S A 102:2063-2068.

Sugatani J, Kojima H, Ueda A, Kakizaki S, Yoshinari K, Gong QH, Owens IS, Negishi M, and Sueyoshi T (2001) The phenobarbital response enhancer module in the human bilirubin UDP-glucuronosyltransferase UGT1A1 gene and regulation by the nuclear receptor CAR. Hepatology 33:1232-1238.

Sugatani J, Nishitani S, Yamakawa K, Yoshinari K, Sueyoshi T, Negishi M, and Miwa M (2005) Transcriptional regulation of human UGT1A1 gene expression: activated glucocorticoid receptor enhances constitutive androstane receptor/pregnane $\mathrm{X}$ receptor-mediated UDPglucuronosyltransferase 1A1 regulation with glucocorticoid receptor-interacting protein 1. Mol Pharmacol 67:845-855.

Tamura K, Inoue K, Takahashi M, Matsuo S, Irie K, Kodama Y, Gamo T, Ozawa S, and Yoshida M (2015) Involvement of constitutive androstane receptor in liver hypertrophy and liver tumor development induced by triazole fungicides. Food and chemical toxicology : an international journal published for the British Industrial Biological Research Association 78:86-95.

Tan TY, Lu CH, Chuang HY, Lin TK, Liou CW, Chang WN, and Chuang YC (2009) Long-term antiepileptic drug therapy contributes to the acceleration of atherosclerosis. Epilepsia 50:1579-1586.

Tang X, Ge L, Chen Z, Kong S, Liu W, Xu Y, Zeng S, and Chen S (2016) Methylation of the Constitutive Androstane Receptor Is Involved in the Suppression of CYP2C19 in Hepatitis B Virus-Associated Hepatocellular Carcinoma. Drug Metab Dispos 44:16431652.

Tian J, Huang H, Hoffman B, Liebermann DA, Ledda-Columbano GM, Columbano A, and Locker J (2011) Gadd45beta is an inducible coactivator of transcription that facilitates rapid liver growth in mice. $J$ Clin Invest 121:4491-4502.

Timsit YE and Negishi M (2007) CAR and PXR: the xenobiotic-sensing receptors. Steroids 72:231-246.

Tschuor C, Kachaylo E, Limani P, Raptis DA, Linecker M, Tian Y, Herrmann U, Grabliauskaite K, Weber A, Columbano A, Graf R, Humar B, and Clavien PA (2016) Constitutive androstane receptor (Car)-driven regeneration protects liver from failure following tissue loss. J Hepatol 65:66-74.

Tzameli I, Pissios P, Schuetz EG, and Moore DD (2000) The xenobiotic compound 1,4-bis[2(3,5-dichloropyridyloxy)]benzene is an agonist ligand for the nuclear receptor CAR. Mol Cell Biol 20:2951-2958.

Ueda A, Hamadeh HK, Webb HK, Yamamoto Y, Sueyoshi T, Afshari CA, Lehmann JM, and Negishi M (2002) Diverse roles of the nuclear orphan receptor CAR in regulating hepatic genes in response to phenobarbital. Mol Pharmacol 61:1-6.

van der Mark VA, Adam AAA, Chang J-C, Oude Elferink RP, Chamuleau RAFM, and Hoekstra $\mathrm{R}$ (2020) Overexpression of the constitutive androstane receptor and shaken 3D-culturing increase biotransformation and oxidative phosphorylation and sensitivity to 
mitochondrial amiodarone toxicity of HepaRG cells. Toxicology and Applied Pharmacology 399:115055.

Wang D, Li L, Yang H, Ferguson SS, Baer MR, Gartenhaus RB, and Wang H (2013) The constitutive androstane receptor is a novel therapeutic target facilitating cyclophosphamide-based treatment of hematopoietic malignancies. Blood 121:329-338.

Wang H and LeCluyse EL (2003) Role of orphan nuclear receptors in the regulation of drugmetabolising enzymes. Clinical pharmacokinetics 42:1331-1357.

Wang Z, Li X, Wu Q, Lamb JCt, and Klaunig JE (2017) Toxaphene-induced mouse liver tumorigenesis is mediated by the constitutive androstane receptor. J Appl Toxicol 37:967975.

Willson TM and Kliewer SA (2002) PXR, CAR and drug metabolism. Nature reviews Drug discovery 1:259-266.

Xie W, Radominska-Pandya A, Shi Y, Simon CM, Nelson MC, Ong ES, Waxman DJ, and Evans RM (2001) An essential role for nuclear receptors SXR/PXR in detoxification of cholestatic bile acids. Proc Natl Acad Sci U S A 98:3375-3380.

Xu P, Hong F, Wang J, Dai S, Wang J, and Zhai Y (2018) The CAR agonist TCPOBOP inhibits lipogenesis and promotes fibrosis in the mammary gland of adolescent female mice. Toxicol Lett 290:29-35.

Yamada T, Okuda Y, Kushida M, Sumida K, Takeuchi H, Nagahori H, Fukuda T, Lake BG, Cohen SM, and Kawamura S (2014) Human hepatocytes support the hypertrophic but not the hyperplastic response to the murine nongenotoxic hepatocarcinogen sodium phenobarbital in an in vivo study using a chimeric mouse with humanized liver. Toxicol Sci 142:137-157.

Yamamoto Y, Moore R, Flavell RA, Lu B, and Negishi M (2010) Nuclear receptor CAR represses TNFalpha-induced cell death by interacting with the anti-apoptotic GADD45B. PLoS One 5:e10121.

Yamamoto Y, Moore R, Goldsworthy TL, Negishi M, and Maronpot RR (2004) The orphan nuclear receptor constitutive active/androstane receptor is essential for liver tumor promotion by phenobarbital in mice. Cancer research 64:7197-7200.

Yan J, Chen B, Lu J, and Xie W (2015) Deciphering the roles of the constitutive androstane receptor in energy metabolism. Acta Pharmacol Sin 36:62-70.

Yang H and Wang H (2014) Signaling control of the constitutive androstane receptor (CAR). Protein Cell 5:113-123.

Yang T, Espenshade PJ, Wright ME, Yabe D, Gong Y, Aebersold R, Goldstein JL, and Brown MS (2002) Crucial step in cholesterol homeostasis: sterols promote binding of SCAP to INSIG-1, a membrane protein that facilitates retention of SREBPs in ER. Cell 110:489500.

Yarushkin AA, Kachaylo EM, and Pustylnyak VO (2013) The constitutive androstane receptor activator 4-[(4R,6R)-4,6-diphenyl-1,3-dioxan-2-yl]-N,N-dimethylaniline inhibits the gluconeogenic genes PEPCK and G6Pase through the suppression of HNF4alpha and FOXO1 transcriptional activity. Br J Pharmacol 168:1923-1932.

Yarushkin AA, Kazantseva YA, Prokopyeva EA, Markova DN, Pustylnyak YA, and Pustylnyak VO (2016) Constitutive androstane receptor activation evokes the expression of glycolytic genes. Biochem Biophys Res Commun 478:1099-1105. 
Yin L, Ma H, Ge X, Edwards PA, and Zhang Y (2011) Hepatic hepatocyte nuclear factor 4alpha is essential for maintaining triglyceride and cholesterol homeostasis. Arterioscler Thromb Vasc Biol 31:328-336.

Yoshinari K, Kobayashi K, Moore R, Kawamoto T, and Negishi M (2003) Identification of the nuclear receptor CAR:HSP90 complex in mouse liver and recruitment of protein phosphatase 2A in response to phenobarbital. FEBS Lett 548:17-20.

Yueh MF, Taniguchi K, Chen S, Evans RM, Hammock BD, Karin M, and Tukey RH (2014) The commonly used antimicrobial additive triclosan is a liver tumor promoter. Proc Natl Acad Sci U S A 111:17200-17205.

Zhai Y, Wada T, Zhang B, Khadem S, Ren S, Kuruba R, Li S, and Xie W (2010) A functional cross-talk between liver $\mathrm{X}$ receptor-alpha and constitutive androstane receptor links lipogenesis and xenobiotic responses. Mol Pharmacol 78:666-674.

Zhang J, Huang W, Qatanani M, Evans RM, and Moore DD (2004) The constitutive androstane receptor and pregnane $\mathrm{X}$ receptor function coordinately to prevent bile acid-induced hepatotoxicity. J Biol Chem 279:49517-49522. 
DMD-MR-2021-000483

\section{Figure Legends}

Figure 1. The diverse biological function of CAR. Without activation, CAR is maintained in the cytoplasm of hepatocytes forming a protein complex with HSP90 and CCRP. Upon activation, CAR is dephosphorylated by PP2A and translocated into the nucleus. Once in the nucleus, CAR 1) forms a heterodimer with RXR and binds to the xenobiotic responsive enhancer module in the upstream region of different target genes resulting in transcription of genes encoding DME, such as CYP2B6, UGT1A1, and SULT1A1; 2) competes with transcription factors, such as FOXO1 and HNF4 $\alpha$, for binding to the promoters of their target genes, including PEPCK1 and G6Pase, repressing energy homeostasis; and 3) interacts with YAP, Gad45 $\beta$, and $\beta$-catenin that are associated with cell proliferation and apoptosis.

\section{Figure 2. Species-specific effects of CAR on energy metabolism and cancer development.}

Schematic illustration of the effects of mouse and human CAR on energy homeostasis and cancer development. It is widely accepted that activation of mouse CAR inhibits hepatic gluconeogenesis and lipogenesis under nutritional challenge. Mouse CAR activation has also been established as a mode of action for hepatocyte proliferation and liver tumorigenesis induced by PB-like compounds. In the case of human CAR, limited data thus far indicate that hCAR activation represses hepatic gluconeogenesis with uncertain effects on lipogenesis. Activation of hCAR does not increase hepatocyte proliferation and the expression of hCAR appears to be negatively related to $\mathrm{HCC}$ prognosis. 


\section{Figure 1}
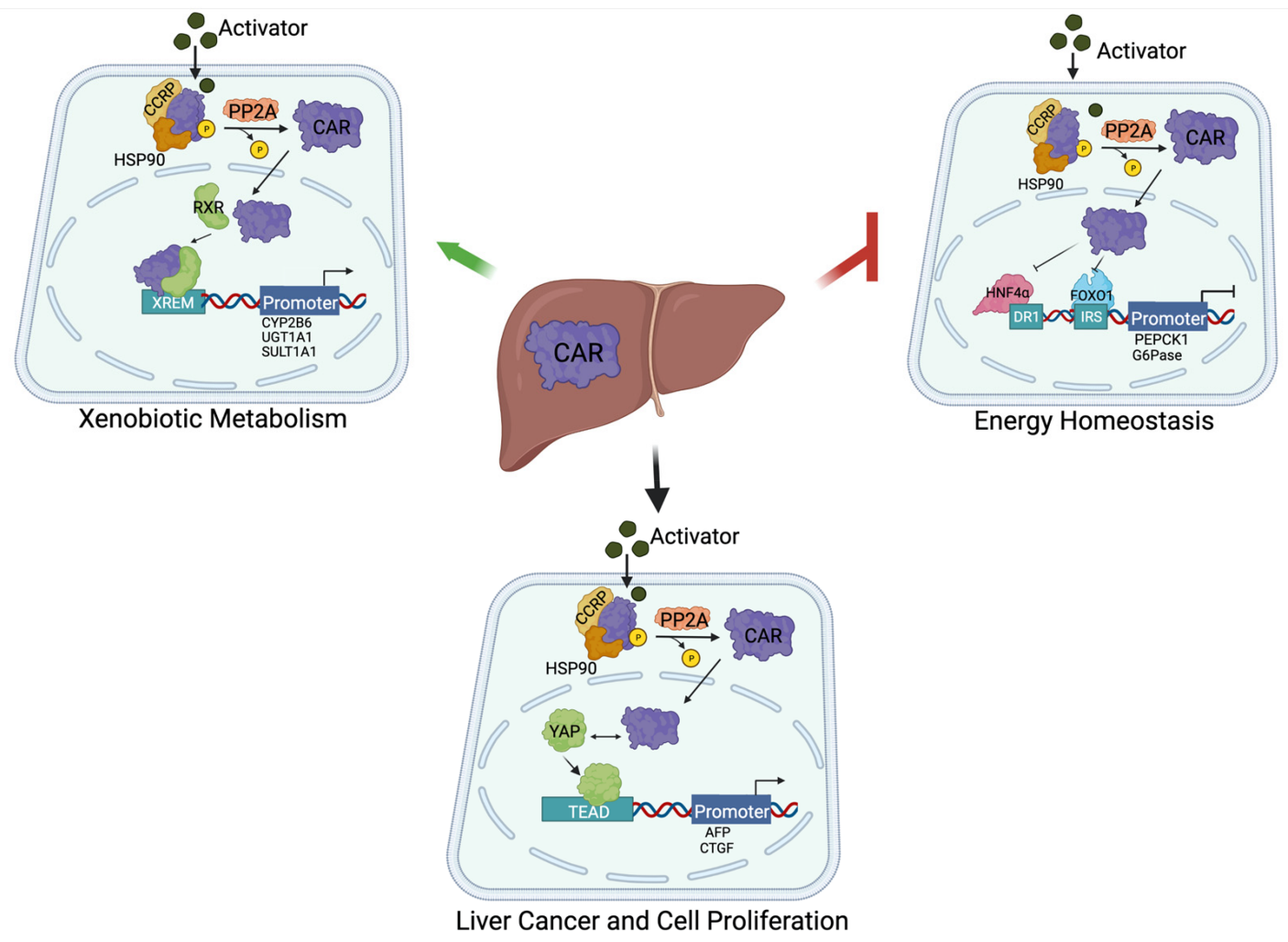


\section{Figure 2}
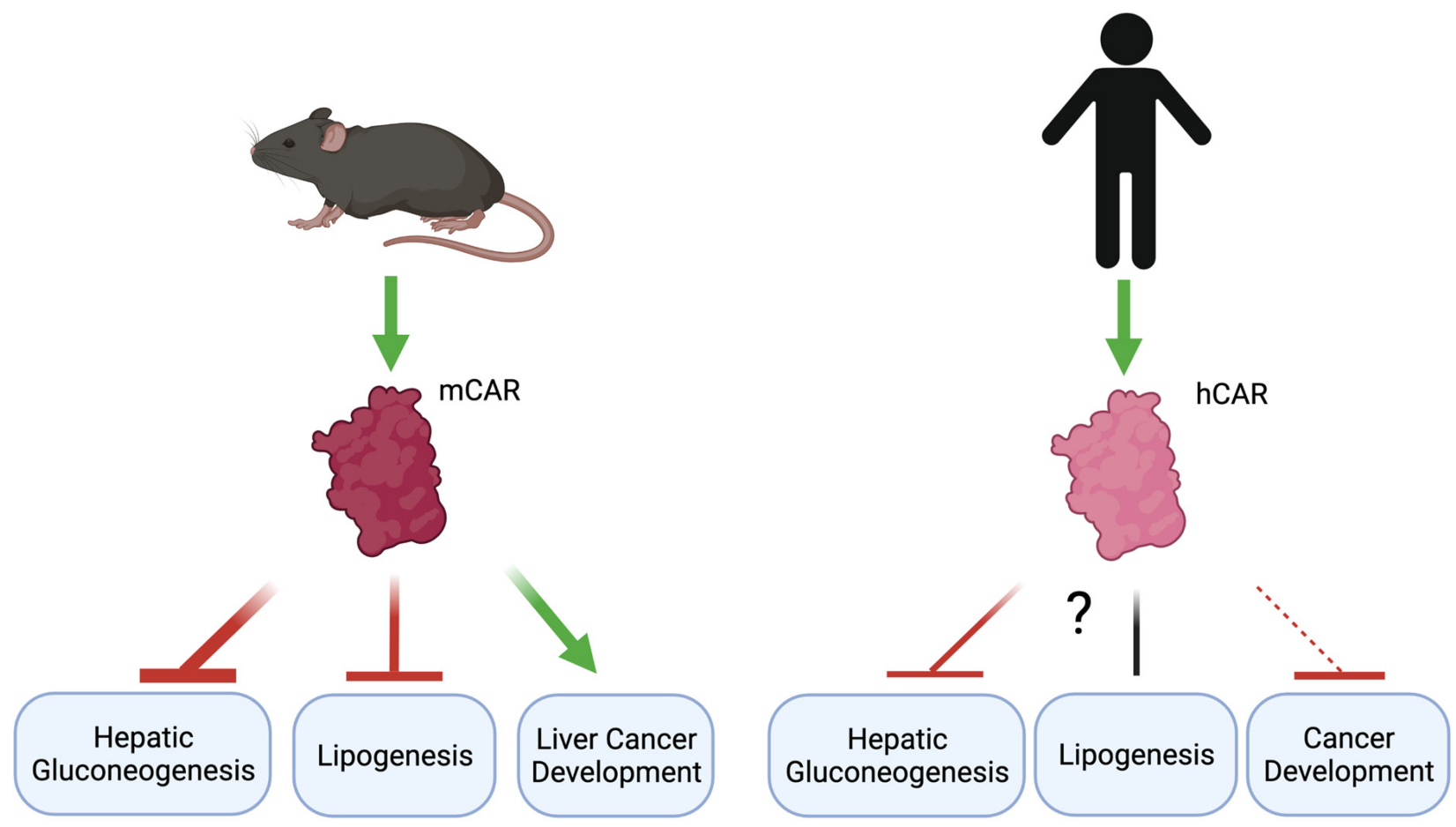